\title{
Modos de vida e modos de beber de jovens indígenas em um contexto de transformações
}

\author{
Ways of life and ways to drink of young indigenous \\ in a transformation context
}

Maximiliano Loiola Ponte de Souza ${ }^{1}$

Suely Ferreira Deslandes ${ }^{2}$

Luiza Garnelo ${ }^{1}$

\footnotetext{
${ }^{1}$ Instituto Leônidas e M aria Deane, Fundação O swaldo Cruz. Rua Teresina 476, Adrianópolis. 69057-070 M anausAM . maximiliano@ amazonia.fiocruz.br

${ }^{2}$ Instituto Fernandes

Figueira, Fundação Oswaldo Cruz.
}

Abstract The interactions among the ways of life and drink of youthsindigenous of a populous place of U pper Rio N egro wereanalyzed through an ethnographic research. I t was used a theoretical model that allowed to decompose and to articulate the social reality in different levels. It was observed that there was a multiplication of the situations in which is possible to drink, that are associated to mechanismsas much of belonging demarcation as of exposition of differencesinter-group. N owadays, youths insert themselves in multiple interaction networks. Through these networks they can create juvenile atmospheres of alcohol consumption, drink far away from the parents and buy industrialized drinks. With the introduction of the school and the abandonment of the initiation rituals, the youth status became uncertain, and it occurs in an ambiguous way the social norms of alcohol consumption, in a context in which there is no consensus in daily practice respect of the possible strategies to regulate juvenile drinking. Through this research, theoretical-methodological alternatives could be suggested to investigate the relationships that are established between the ways of life and the production of the health and disease, incorporating in this analysis the culture (and its transformation), the daily life (and its contradictions), the people (and its subjectivities). Key words South American Indians, Youth, Life's conditions, Alcohol consumption
Resumo Através de uma pesquisa etnográfica, analisaram-se as interações entre os atuais modos devida e de beber dejovens indígenas de uma populosa localidade do Alto Rio N egro. Para tanto, se utilizou um modelo teórico que permitiu decompor e articular a realidade social em diferentes níveis. Observou-se que houve a multiplicação das situações em que se bebe, que são associadasa me canismos tanto de demarcação de pertencimento como de explicitação de diferenças intergrupais. Atualmente, os jovens inserem-se em múltiplas redes de interação. Através delas, podem criar ambientesjuvenis deconsumo deálcool, beber longe dos pais e comprar bebi das industrializadas. Com a introdução da escola eo abandono dos rituais de iniciação, o status do jovem tornou-se incerto e sobre ele incidem de forma ambígua as normas sociais de consumo de álcool, num contexto no qual não há consenso na prática cotidiana a respeito das possíveis estratégias para regular o beber juvenil. Através desta pesquisa, puderam-se aventar alternativas teórico-metodológicas para investigar as relações que se estabel ecem entre os modos de vida ea produção da saúde e da doença, incorporando a esta análise a cultura (e sua transformação), a vida cotidiana (e suas contradições), as pessoas (e suas subjetivi dades).

Palavras-chave Índios sul-americanos, Juventude, Condições de vida, Consumo de álcool 
Introdução

A região do Alto Rio N egro, localizada no noroeste amazônico, é habitada por cerca de 30.000 indígenas ${ }^{1}$, distribuídos em aproximadamente 22 etnias. Estes compartilham o uso do caxiri (bebida alcoólica fermentada, à base de mandioca e frutas) ${ }^{2}$, que era consumido particularmente nas festas de troca ou dabucuris ${ }^{3}$; e nos rituais de iniciação masculina, situações de grande significado simbólico nestecontexto sociocultural ${ }^{4,5}$. N osmais de três séculos de contato interétnico, a cachaça também passou a ser consumida, as situações festivas foram incrementadas ${ }^{6}$ e, em diversos grupos, houve a supressão do rito pubertário $0^{7,8}$. Esta última transformação está associada, em parte, à introdução dos colégios internatos, pelos missionários salesianos. Enclausurados nestas instituições, criadas para catequizá-los e transformá-los em agentes da civilização, os jovens não estavam em companhia dos mais velhos no momento em que deveriam ser iniciados?

lauaretê, distrito rural do município de São Gabriel da Cachoeira, é uma "cidade" indígena”, localizada às margens do rio U aupés, maior afluente do Rio N egro. Ali foi implantado um internato quefuncionou, nesteregime, de 1929 a 1986, quando foi transformado em externato. D esde então, famílias de diferentes locais eetnias passaram a migrar para lauaretê, para dar continuidade à escolarização dos filhos ${ }^{7}$, visto que nas pequenas comunidades não há oferta de ensino médio. Concomitantemente ao incremento demográfico, a localidade vem sendo urbanizada. Atualmente, dispõe deeletrificação, tel efonia, comércios, quartel do exército e agência dos correios que presta serviços bancários.

As mudanças nos padrões de moradia e hábitos dos gruposindígenas residentes em lauaretêa tornam um local prototípico para o estudo das relações entre modos de vida eo processo saúde/ doença, objeto de interesse crescente no campo da saúde coletiva. Porém, os autores que abordam estecampo através das ferramentas da epidemiologia clássica não raramente reduzem os modos de vida a variáveis socioeconômicas e demográficas, agrupando-as em indicadores compostos. Estes se mostram pouco eficazes em apreender a multivariedade do real eincorporar dimensões subjetivo-valorativas e culturais $s^{9,10}$, que são essenciais para a compreensão dos fatores que influenciam a produção da saúde e da doença ${ }^{11}$.

A presenta-seaqui um estudo exploratório que investiga as dimensões qualitativas da vida social de lauaretê, associadas ao consumo de bebidas alcoólicas pelos jovens indígenas, visto ali como socialmente problemático. Em lauaretê, a afirmação corrente é que os jovens bebem cada vez mais cedo, de modo mais frequente e violento, $\mathrm{e}$ que há dificuldades coletivas em se lidar com este comportamento.

0 objetivo deste trabal ho é analisar as possíveis interações entre as atuais condiç̧̃̃es de vida da população indígena de lauaretê e o modo de beber dos jovens indígenas, reconhecendo a intrínseca relação que se estabel ece entre o contexto sociocultural, a organização social e as estratégias deenfrentamento, local mente disponíveis, para este problema.

\section{Pressupostos teóricos}

Almeida-Filho entende os modos devida como 0 "conjunto articulado de práticas cotidianas" pode ser decomposto em condições de vida e estilo de vida. As primeiras se referem às condições de produção e circulação de bens e serviços, de forma direta, ou via políticas públicas compensatórias. Já o segundo deve ser compreendido como o conjunto de comportamentos, hábitos e atitudes de indivíduos e grupos sociais.

No caso deste trabalho, os jovens compõem o grupo social de interesse. A juventude é aqui entendida como "uma representação ou criação simbólica, fabricada pelos grupos sociais ou pelos próprios indivíduos tidos como jovens, para significar uma série de comportamentos e atitudes a eles atribuídos"12. Já a conduta juvenil priorizada para análise é o consumo de bebidas alcoólicas. Analiticamente, o consumo deálcool pode ser decomposto em diferentes categorias. Entende-se por processo de alcoolização os modos e significados queo beber adquireem um grup $0^{6,13}$, em determinado contexto. Já problemas relacionados ao uso do álcool relacionam-sea um modo de beber, tido socialmente como associado a efeitos adversos, sendo fortemente influenciado por condicionantes socioculturais e históricos ${ }^{6,14}$.

Outro conceito-chaveéo deespaço, entendido como a expressão geográfico-territorial de relações históricas, sociais, econômicas, culturais e ecológicas, travadas entre sociedades humanas eoutros fatores bióticos e abióticos ${ }^{15-17}$. Este conceito tem representado uma via teórico-metodológica integrativa para se entender as correlações entre vida social e desigualdades sociais e sanitárias. Nas sociedades indígenas, a socialização e a organização da vida são moldadas pelas relações de parentesco, que configuram as estratégias tradicionais de ocupação do espaço (territorialização), atualmente modificadas pela força 
das relações interétnicas, influenciando o modo juvenil de beber, como se demonstrará.

\section{Metodologia}

Realizou-se uma etnografia, entendida como uma "pesquisa de campo com observação prolongada [...], seguida pela produção de dados em condições discursivas e dialógicas, expressos através de formas textualizadas"18. 0 trabalho de campo, que durou seis meses, teve prévia autorização do Comitê Nacional deÉtica em Pesquisa.
Em campo, privilegiou-se observar o cotidiano dos jovens que vivem em I auaretê; quando, como, onde, com quem e o que eles bebem; os discursos sobre o modo deles beberem e as estratégias empregadas, ou propostas, para regular este consumo.

0 modelo analítico desenvolvido por Contandriopoulos ${ }^{11}$, no qual decompõe o contexto social níveis distintos e inter-relacionados, para apreender as interfaces entre condições de vida e saúde, foi adaptado para atender aos propósitos desta pesquisa (Figura 1). 0 nível mais abrangente considerado foi a cultura indígena rione-

Cultura rionegrina

- Modos e significados de beber

- Rituais de iniciação

Organização sociopolítica de Iauaretê

- Crescimento demográfico

- Convivência multi-étnica

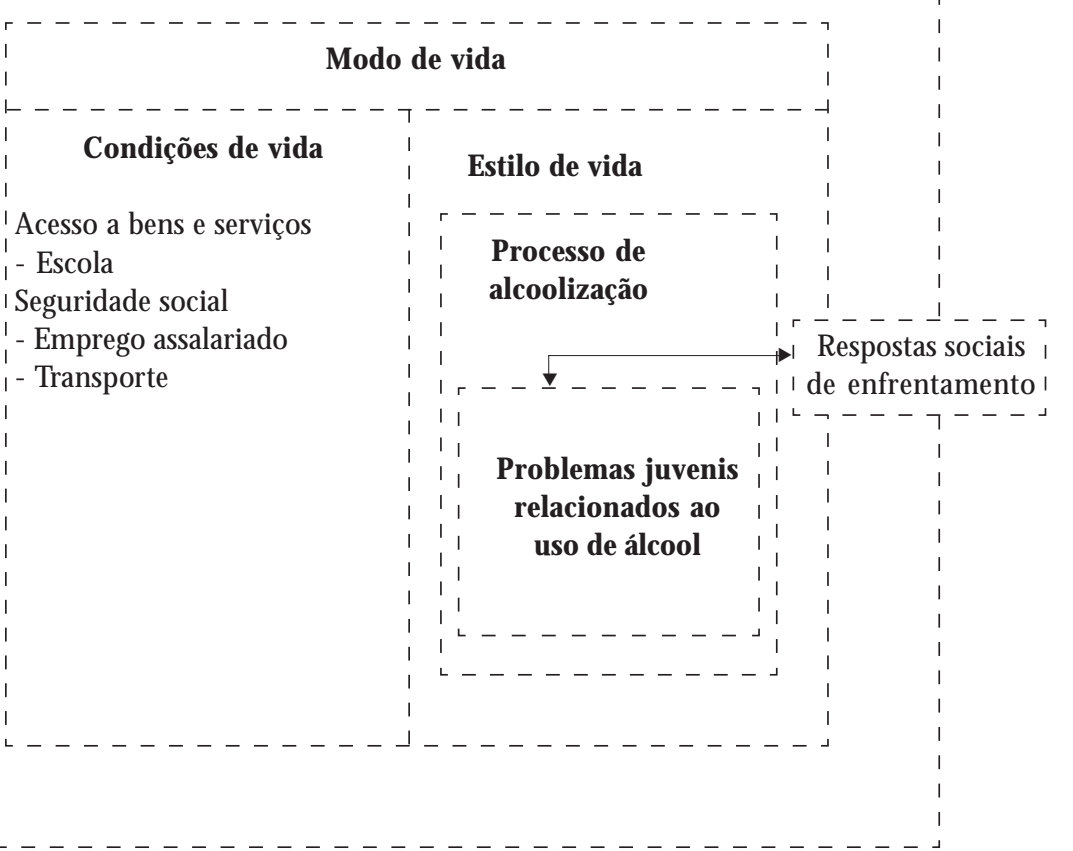

Figura 1. M odelo analítico para compreensão das relações entre o contexto social e os problemas juvenis relacionados ao uso de álcool (adaptado a partir de Cotandriopoulus ${ }^{11}$ ). 
grina, entendendo que as produções culturais traçam os contornos dos valores e comportamentos em uma sociedade. Buscou-se uma aproximação com os modos e significados, implícitos ou explícitos, do consumo de bebidas alcoólicas, nos mitos e ritos rionegrinos, entendidos como marcadores culturais que orientam normas de comportamento. I gualmente foram valorizados os rituais de iniciação como demarcadores de mudança de status social na população mais jovem.

No nível organização sociopolítica del auare tê, seexplorou o impacto do crescimento demográfico e da convivência multiétnica nas formas de interação social, e suas possíveis relações com o incremento de situações em que se consomem bebidas al coólicas.

As condições de vida foram associadas, no contexto de lauaretê, ao acesso a diferentes bens e serviços, como escola formal, seguridade social, empregados assalariados e transportes, ou seja, às inovações contemporâneas do viver indígena. Jáno estilo devida, alocou-seo consumo debebidas alcoólicas, tanto nos aspectos que se referem ao processo de alcoolização, quanto aos proble mas juvenis relacionais ao uso desta substância.

Respostas sociais de enfrentamento foram entendidas como "mediadas pela consciência individual e coletiva acerca das possibilidades de modificação dos problemas" ${ }^{10}$; foram remetidas à movimentação social estruturada em torno do beber-problema.

\section{Resultados ediscussão}

\section{Culturas rionegrinas}

N estas culturas, definem-se como consanguíneos os descendentes de um grupo de irmãos ancestrais, que partilham uma língua comum. Os parentes estão agrupados em unidades sociais menores, sibs, que dispunham, tradicionalmente, de locais específicos demoradia, nos quais erguiam suas casas comunais (malocas). Os consanguíneos devem buscar esposas junto a falantes de outra língua que residiriam em outras localidades ${ }^{2,3}$.

$\mathrm{Na}$ mitologia, os cunhados potenciais, ou reais, são representados como inimigos, cuja periculosidade pode ser "domesticada", mas jamais anulada, pelo estabelecimento das trocas matrimoniais ${ }^{2}$.

Conforme a tradição, o consumo ritual de caxiri teria a potencialidade de promover a re- conciliação dos inimigos, mesmo temporariamente. Entretanto, nestas mesmas ocasiões, conflitos eclipsados no cotidiano podem emergir na forma de agressão. Assim, o consumo coletivo de bebidas alcoólicas é um importante elemento da vida social, que tanto pode atenuar quanto exacerbar as diferenças ${ }^{19}$.

Os dabucuris são festas-rituais, fortemente associadas às trocas matrimoniais, nas quais se consome caxiri e trocam produtos ${ }^{3}$. A capacidade de oferta de grandequantidade decaxiri pelos membros de uma aldeia evidencia o prestígio da liderança. Habitualmente, se estabelece uma rivalidade amigável, em que os visitantes são desafiados a consumir toda bebida, ao passo que estes bravateiam, afirmando que o caxiri ofertado é pouco, em comparação aos regalos trazidos para os anfitriões ${ }^{7,20}$.

Outrora, a plena participação nestas festas se dava após o ritual de iniciação, que ocorria entre doze e treze anos ${ }^{4}$. Durante o processo preparatório, o iniciando era enclausurado e emergia no universo cultural do grupo. Nas festas, o jovem iniciado passava a usar pinturas faciais e os adornos específicos de seu sib, diferenciando-se dos não-iniciados (crianças) ${ }^{4}$. A capacidade de ingerir grandes quantidades de caxiri e dançar por horas era indicativa da virilidade juvenil, sendo objeto de orgulho para os seus parentes ${ }^{21}$.

Somente após o ritual de iniciação, que propiciava a plena identificação como membro do grupo, o jovem estaria apto à busca de parceiras sexuais legítimas, em condição de se tornarem esposas. E apenas após o nascimento de seus fiIhos, o iniciado seria considerado adulto?

\section{Organização sociopolítica de I auaretê}

Em 2007, a população dessa localidade era estimada em 2.779 habitantes, o quíntuplo daquela existente em 19757. Lá estão representados praticamente todos os grupos étnicos da região. Em lauaretê, os pequenos e dispersos assentamentos tradicionais, formados por homens de um mesmo sib, foram substituídos por populosos bairros indígenas multiétnicos.

lauaretê está divida em dez bairros, ou vilas. Cada um possui capela, com seu santo padroeiro, um salão comunitário, ondese realizam festas eoutras reuniões; figuras derelevância social como o capitão (chefe político da comunidade), animador, catequista, agente comunitário de saúde e times esportivos de jovens, quecompetem entresi.

Nos bairros de lauaretê, observa-se uma releitura dos ideais de autonomia eindependência 
dos pequenos e dispersos grupos de parentesco, que operam no sentido de evitar a fusão e a perda de limites entre as unidades sociai ${ }^{18}$. Ali, os grupos de vizinhança, formados por parentes e não-parentes, buscam manter relações de apoio e solidariedade, em contraposição aos moradores de outros bairros. A proximidade territorial substitui, em certa medida, as formas de socialização típicas da consanguinidade.

Cada vila éum território específico, queinterage com outros territórios-vilas que formam 0 tecido urbano. Em lauaretể, como em outros contextos urbanos do Alto Rio $\mathrm{Negro}^{8}$, o modo de vida aldeã é a referência contra a qual a vida citadina é contrastada. Assim, as vilas de lauaretê são estruturadas, simultaneamente, segundo as relações de parentesco e pelos novos padrões de assentamento advindos do contato interétnico.

A realização de festas com consumo de bebidas alcoólicas é um meio recorrentemente utilizado na construção e manutenção da identidade grupal. Convidar moradores de outras vilas para suas festas, ou visitá-los em suas comemorações, preserva a distinção entre "nós" e os "outros", ainda que para diluí-las, parcial e temporariamente, no consumo de bebidas alcoólicas.

A partir de sexta-feira ocorrem, concomitantemente, festas nos salões das diferentes vilas. A idéia de uma festa organizada com todos os moradores não parece fazer sentido. Quando 0 pároco da missão salesiana resolveu que a festa de São Miguel Arcanjo seria coletiva, os moradores da vila de mesmo nome realizaram no fim de semana anterior à cel ebração oficial, uma festa própria, demarcando sua especificidade frente às outras vilas.

Além das festas comunais, proliferam outras formas de socialização, mais ligadas ao modo de vida urbano, como as comemorações cívico-religiosas (dia da independência, do índio, carnaval) ${ }^{6}$, e as festas "particulares", como os casamentos e aniversários. N estas últimas, as interações entre os convivas podem congregar redes de vizinhança, independentemente do pertencimento a bairros determinados. Há, portanto, uma pulverização dos espaços de convivência que proliferam as festas e a ampliam a oferta de bebidas alcoólicas.

\section{Condições de vida}

Fomos educados

no internato dos missionários

No contexto rionegrino, com a introdução da escola formal, dificultou-se a participação dos alunos nos rituais de iniciação e os apartou dos mais velhos. Estes fatos tanto minaram as principais formas de aprendizado dos conhecimentos e valores culturais indígenas, quanto os mecanismos tradicionais de definição do status de adulto naquelas sociedades.

Com o fim dos rituais de iniciação, com o prolongamento dos anos escolares e a postergação do casamento, vem-se construindo umanova categoria social, temporalmente dilatada e de limites imprecisos, a de "juventude". 0 consumo de caxiri era al go esperado de um jovem iniciado de doze ou treze anos ${ }^{21}$. Entretanto, anciãos de lauaretê, que foram alunos do internato, dizem ter iniciado o uso debebida com idade mais avançada, pois os padres não Ihes permitiam beber.

Com o fim do internato, os jovens passam a beber mais cedo, como "antigamente", para espanto de seus pais e avós. Isso ocorre num contexto no qual aquele que é chamado de jovem é também associado à categoria de aluno e, conforme uma liderança indígena, "quem está nesta categoria ainda é criança".

Eles têm os amigos da escola

$\mathrm{Na}$ escola, convivem jovens de diferentes vilas. Facilmente um jovem terá informações sobre situações de consumo de bebidas alcoólicas que ocorrem nas diferentes vilas de lauaretê. Ocorrendo uma festa na vila de um "amigo da escola", um jovem podeser convidado a beber caxiri. Uma vila distinta da sua é um lugar de "outras" pessoas. A relação com os amigos da escola Ihe permite uma aproximação menos tensa, porém, o salão comunitário, com suas formalidades, sobretudo no começo da festa, éum espaço pouco convidativo. De forma mais comum, antes de se dirigirem ao local da festa, os jovens ficam bebendo caxiri, na casa de um amigo, residente local.

Aos sábados, as festas iniciam por volta de 13 horas, como capitão da vila explicando osmotivos da festa e pedindo que todos bebam juntos e tranquilos. N esta hora, praticamente não há jovens no salão. Eles estão nas casas, seja nas suas, recebendo visitas, ou nas de outros, sendo visitante.

Pais, mães elideranças não aprovam esta prática. Entretanto, dizem que não podem expulsar os jovens visitantes e que não Ihes oferecer caxiri daria a entender que têm inimizade com eles ou com seus pais. Além disso, caso o filho disponha de pouco caxiri para oferecer aos amigos, isso seria algo vexatório, subentendendo sovinice (recusa a partilha) ou preguiça (sobretudo da mãe do jovem, que não teria preparado uma boa quantidade da bebida). 
A depender do ponto de vista, o jovem anfitrião é representado como alguém que "desencaminha" o outro jovem ao chamá-lo para sua casa, obrigando- 0 a beber grandes quantidades de caxiri. Alternativamente, o visitante pode ser descrito como alguém que se aproveita das regras de etiqueta local para beber o "pouquinho" de caxiri que a mãe de seu amigo preparou para levar para o centro comunitário.

A ida à casa do amigo permite tanto uma entrada menos abrupta num espaço da alteridade (o salão comunitário), como multiplica as oportunidades de beber, criando-se um espaço juvenil para esta prática, diferenciado do ambiente de consumo coletivo. Possuidores de uma rede heterogênea de contatos nos diversos bairros, os jovens passam, sem maiores dificuldades, a transitar de vila em vila, consumindo caxiri.

Aqui é proibido,

mas muitos índios estão trazendo

Apesar da venda de cachaça ser proibida em terra indígena ${ }^{22}$, é fácil encontrar este produto em lauaretê. A relativa facilidade de deslocamento entre lauaretê e a sede municipal, propiciada pela grande circulação de barcos, facilita a entrada de cachaça, seja para consumo pessoal ou para venda.

Diferentemente do observado em outras localidades da região ${ }^{6}, 0$ acesso dos jovens a esta bebida parece ser maior, ainda que os preços sejam elevados. Isso ocorre num contexto no qual é maior a circulação de dinheiro. Para comprar cachaça, os jovens podem valer-se das amizades com militares indígenas; vender produtos extrativistas; ludibriar aposentados ou coagir parentes idosos que "não vêm seu dinheiro, porque os netos pegam tudo", conforme um septuagenário. Em algumas situações, observou-se que os pais ou avós simplesmente davam dinheiro para os jovens, a fim de "fazê-los felizes". Uma vez obtido o dinheiro, os jovens costumam se cotizar e comprar cachaça.

Assim, a crescente monetarização das relações, associada ao incremento da circulação de pessoas e produtos entre lauaretê e São Gabriel da Cachoeira, é um fator que vem confluindo para facilitar 0 acesso dos jovens as bebidas alcoólicas industrializadas.

Respostas sociais de enfrentamento

Dados etnográficos apontam queno Alto Rio Negro, como em outras sociedades indígenas, 0 controlesobre o beber éintrinsecamenterelacio- nado à disponibilidade da bebida ${ }^{6,23}$. Analogamente, em lauaretê, as estratégias aventadas para lidar com o beber-problema juvenil buscavam restringir 0 acesso a bebidas.

Porém, durante a pesquisa de campo, observou-se que estas propostas não eram efetivadas na prática. Os dados mostram que as festas cumprem uma função muito mais ampla que o congraçamento entre os presentes. Assim, a redução das festas demandaria a alteração de estruturas culturais que demarcam a identidade dos grupos e as relações de prestígio das lideranças. A redução, ou supressão, desses eventos obrigaria as lideranças a buscar novos caminhos para apaziguar diferenças e circunscrever hostilidades. Trata-se de uma difícil tarefa, sobretudo se consideramos a fragilidade dos laços que unem os moradores das vilas, que se valem principalmente da condição de coresidentes para manter a coesão social necessária à vida comunal.

Outro aspecto relevante está ligado à participação feminina nesse contexto. Tradicionalmente, a mulher é responsável pela produção de alimentos e bebidas, o caxiri inclusive. Provêlos em grande quantidade é al go esperado e demandado do pólo feminino dos núcleos familiares 8 . Suprimir a produção de caxiri implicaria em solapar o ideal do zelo feminino com a roça e manufatura de produtos derivados da mandioca.

Ademais, nas últimas décadas, as mulheres de lauaretê passaram a auferir lucro com a venda do caxiri. Iniciativas para reduzir sua venda geraram descontentamento entre as mulheres, porqueessa fonte derenda representa um aporte financeiro importante para a manutenção das unidades domésticas, num contexto de progressiva ampliação da dependência de bensindustrializados de consumo.

No plano político, algumas lideranças associam a proibição legal de entrada da cachaça em área indígena a uma manifestação do sistema jurídico tutelar, queconsidera o índio legalmente incapaz. Alguns indígenas que se manifestam a favor da proibição comercializam cachaça em lauaretê. Outros são a favor da proibição da entrada desta bebida, mas caso tenham acesso a ela, costumam consumi-la. Em síntese, estaéuma questão em torno da qual é difícil se construir um único consenso.

Por fim, um grupo minoritário de lideranças aponta a necessidade de se repensar não apenas o modo de beber dos jovens, mas o próprio modo de se viver em lauaretê. Posta em prática por alguns anciãos, observou-se uma abordagem baseada na idéia de que o controle dos ex- 
cessos alcoólicos dos jovens passa pela revalorização do respei to à hierarquia ritual característica do modo tradicional de vida ${ }^{2,3}$, pelo aprendizado dos mitos, das músicas, danças e outras práticas ancestrais que vem caindo progressivamente em desuso na região. Fiéis à sua proposta, esses anciãos vêm investindo no ensino de danças e mitos para os jovens, utilizando, para tal, 0 espaço interior de malocas reconstruídas por lideranças das associações indígenas. Seu trabaIho éapoiado por uns, criticados por outros. Para alguns, o mundo mudou e este tipo de conhecimento não teria mais serventia. Para estes anciãos, o mundo mudou eé por isso que concebem a possibilidade de mudança da situação atual de lauaretê, e vêem no retorno às tradições uma alternativa para promoção de mudanças sociais.

\section{Consideraçõesfinais}

Em lauaretê, cada vila-bairro é vista como uma localidade autônoma, operando em moldes semelhantes ao de uma aldeia indígena, alternando alianças edisputas com consanguíneos eafins, num processo intensificado pela proximidade e pela alta densidade demográfica. N estecontexto, multi plicam-se as situações em que se bebe, que remetem à criação emanutenção de sentimentos depertencimento ededemarcação de diferenças, fazendo parte dos mecanismos sociais de gerenciamento de conflitos.

A inserção da juventude no tecido social é precária, situando-se a meio caminho entre a posição chancelada pela tradição (recém-iniciado, na ausência deini ciação) eaquela gerada pela colonização (estudante-infantilizado). Ademais, com os novos padrões de territorialização, reordenam-se as formas de interação entre os subgrupos de jovens e suas famílias. Sai do primeiro plano o pertencimento à descendência de ancestrais comuns esetornam preponderantes os grupos de vizinhança ( vilas, formadas por parentes e não parentes que se tornam coresidentes), de ami gos da escola (moradores dos diferentes bai $r$ ros) e outros.

Neste cenário, os jovens estão inseridos em múltiplas redes deinteração social, queigualmente têm no consumo grupal de bebidas alcoólicas um mecanismo de expressão dealianças. Através destas redes, os jovens podem se cotizar para comprar bebida (caxiri ou cachaça), beber longe do olhar dos pais quando vão para casas de amigos em outras vilas e criar um ambiente juvenil de consumo.

Ao incidirem nestes jovens destatus ambíguo e de redes de interação amplas, as regras de etiqueta social tornam-se inevitavelmente contraditórias. Por um lado, sendo estudantes, são equiparados a crianças, que não deveriam beber; tal pensamento é influenciado pela experiência dos mais velhos como alunos do internato missionário. Por outro lado, demanda-se dos jovens que ingiram grandes quantidades de caxiri, demonstrando tanto sua virilidade, como sua confiança e respeito pelos anfitriões. Valendo-sedestas mesmas regras, os jovens reivindicam quelhes seja servido caxiri, seja nos contextos de consumo coletivo, nos salões comunitários, ou microgrupais, na casa de amigos. Ademais, o dinheiro obtido pelos jovens torna-os compradores de bebida, inserindo-os nas relações decomércio que geram renda para outras famílias, num contexto de crescente monetarização.

Assim, observa-sequeem l auaretêvêm ocorrendo importantes transformações na organização social enas condições de vida, que se refletem nos modos de beber, particularmente daqueles que são chamados de jovens. Porém, diferentemente do senso comum local, o modo de beber juvenil não se configura como resultante de um sistema cultural combalido e perdido. Alternativamente, éesse próprio sistema que configura e cria condições de possibilidade para esta prática juvenil, mesmo que para isso pague-se um preço, na medida em que os mecanismos tradicionais/comunais de coibição deexcessos são incapazes de operar plenamente no estilo urbanizado de vida praticado em lauaretê.

Através da etnografia realizada, evidenciaramseas relações quese estabelecem entreo modo de vida indígena contemporâneo e a representação e configuração de agravos à saúde, localmente identificados como prioritários, como no caso do beber-problema juvenil. Entende-seque, através desta pesquisa, puderam-se aventar alternativas teórico-metodológicas para investigar as relações que se estabelecem entre os modos de vida e a produção da saúde e da doença, incorporando a esta análise a cultura (e sua transformação), a vida cotidiana (e suas contradições), as pessoas (e suas subjetividades). 


\section{Colaboradores}

M LP Souza participou da pesquisa de campo, da concepção e da redação final do artigo. L Garnelo e SF Deslandes participaram de todas as etapas acima, com exceção da pesquisa de campo.

\section{Referências}

1. Pagliaro H, Azevedo M M, Santos RV. Demografia dos povos indígenas no Brasil. Rio de Janeiro: Fiocruz; 2005.

2. Jackson JE. The fish people: linguistic exomamy and Tukanoan identity in Northwest Amazon. Cambridge: Cambridge University Press; 1983.

3. Chernela JM. The Wanano Indians of the Brazilian Amazon: a sense of space. Austin: University of Texas Press; 1993.

4. Hugh-Jones $\mathrm{C}$. From the milk river: spatial and temporal processes in N orthwest Amazonia. Cambridge: Cambridge University Press; 1979.

5. Hugh-Jones, S. The palm and the pleiades: Initiation and Cosmology in N orthwest Amazonia. Cambridge: Cambridge University Press; 1979.

6. Souza M LP, Garnelo L. Quando, como e o que se bebe: 0 processo de alcoolização entre populações indígenas do Alto Rio Negro, Brasil. Cad Saude Publica 2007; 23(7):1640-1648.

7. Andrello G. Cidade do índio: transformações e cotidiano em Iauaretê. São Paulo: UNESP/ISA; 2006.

8. Lasmar C. De volta ao lago de leite: gênero e transformação no Alto Rio N egro. São Paulo: UNESP/ISA; Rio de Janeiro: NUTI; 2006.

9. Almeida-Filho N. Modelos de determinação social das doenças crônicas não-transmissíveis. Cien Saude Colet 2004; 9(4):865-884.

10. Castellanos PL. Epidemiologia, saúde pública, situação de saúde e condições de vida: considerações conceituais. In: Barata RB, organizadora. Condições de vida e situação de saúde. Rio de Janeiro: Abrasco; 1997. p. 31-75.

11. Cotandriopoulus AP. Pode-se construir modelos baseados na relação entre contextos sociais e saúde?. Cad Saude Publica 1998; 143(1):199-204.

12. Groppo LA. Juventude: ensaios sobre sociologia e história das juventudes modernas. Rio de Janeiro: Difeli; 2000.

13. Menendez EL. El proceso de alcoholización: revisión crítica de la producción socioantropológica, histórica y biomédica en América Latina. Cuaderno de la Casa Chata 1982; 57:61-94.
14. Edwars G, Marshall EJ, Cook CCH. O tratamento do alcoolismo: um guia prático para profissionais de saúde. 3a ed. Porto Alegre: Artes M édicas; 1999.

15. Sabroza PC, Toledo L, O sanai CH. Organização do espaço e os processos endêmico-epidêmicos. In: Leal MC, Sabroza PC, Rodriguez RH, Buss PM, organizadores. Saúde, ambiente e desenvolvimento. 1 a ed. Rio de Janeiro: Abrasco/Hucitec; 1992. p. 56-77.

16. Breilh J, Granda E. Os novos rumos da epidemiologia. In: Nunes ED, organizador. As Ciências Sociais em Saúde na América Latina: tendências e perspectivas. Brasília: Organização Pan-Americana da Saúde; 1985. p. 141-153.

17. Barreto ML. A epidemiologia, sua história e crises: notas para pensar o futuro. In: Costa DC, organizador. Epidemiologia: teoria e objeto. Rio de Janeiro: Abrasco/Hucitec; 1990. p. 19-38.

18. Clifford J. A experiência etnográfica. Antropologia e literatura no século XX. Rio de Janeiro: Editora da UFRJ; 2002.

19. Souza MLP. Alcoolização e violência no Alto Rio Negro [dissertação]. M anaus (AM): Universidade Federal do Amazonas; 2004.

20. Hill J. Wakuenai cerimonial exchange in northwest Amazon. J Lat Am Lore. 1987; 13(2):183-224.

21. Goldman I. The Cubeo: Indians of the northwest Amazon. Urbana: University of Illinois Press; 1963.

22. Brasil. Lei no 6.001 de 19 de dezembro de 1973. Dispõe sobre o Estatuto do Índio. Diário Oficial da União 1973; 21 dez.

23. Kunitz SJ, Levy JE. Drinking careers: a twenty-fiveyear study of three Navajo populations. New Haven/ London: Yale University Press; 1994.

\footnotetext{
Artigo apresentado em 09/03/2009

A provado em 16/06/2009

Versão final apresentada em 22/06/2009
} 